\section{A CHEGADA DE UM IRMÃO ADOTIVO: PERCEPÇÕES E EXPERIÊNCIAS}

\author{
The Arrival of one Brother Adoptive: Perceptions and \\ Experiences
}

\author{
La Llegada de uno Hermano Adoptivo: Percepciones y \\ Experiências
}

\section{L'Arriveé d'un Frère Adoptif: Perceptions et Expériences}

Artigo Original

\section{Resumo}

Esta pesquisa teve como objetivo geral investigar as percepções e vivências, na perspectiva de filhos biológicos, diante da chegada de um (a) irmão (ã) adotivo (a). Foram entrevistados sete adultos, na faixa etária entre 19 e 40 anos, que possuíam ao menos um (a) irmão (ã) adotado (a). A entrevista foi analisada de acordo com a técnica de análise de conteúdo. Observou-se, especialmente no início, ambivalência de sentimentos e foram necessárias readaptações na família para a inserção do novo membro, mas a convivência alicerçou a relação entre os irmãos. A grande diferença de idade entre alguns irmãos levou o filho biológico a se portar como irmão parental. $\mathrm{O}$ tratamento dispensado pelos pais aos filhos existentes, bem como a preparação desses foram essenciais para a aceitação da criança adotada. Pode-se concluir que, na maioria dos casos, não se percebeu diferença pelo fato de a fratria ser constituída pela via da consanguinidade ou da adoção, pois são os vínculos afetivos entre pais e filhos que determinam e mobilizam tanto as rivalidades quanto as fraternidades.

Palavras-chave: adoção; irmãos; pais; relacionamento fraterno.

\begin{abstract}
This research aimed to investigate the perceptions and experiences of biological sons with the arrival of an adoptive brother. Seven adults were interviewed, aged between 19 to 40 years, who had at least one adoptive brother. The interviews were analyzed according to content analysis. Is was observed that, especially initially, feelings of ambivalence and readjustments in the family were necessary for the insertion of the new member, but coexistence founded the relationship between brothers. The great age difference between some brothers took the biological child to behave as parental brother. The treatment given by parents to existing children, as well as the preparation of these were essential to the acceptance of the adopted child. One can conclude that, in most cases, no difference was perceived in phratry by way of consanguinity or adoption as the emotional bonds between parents and children determine and mobilize both rivalries as fraternities.
\end{abstract}

Keywords: adoption; siblings; parents; fraternal relationship

\section{Resumen}

Esta investigatión tuvo como objetivo investigar las percepciones y experiencias, derivadas de la llegada de un hermano adoptado en la família. Habia siete adultos entrevistados, con edades compreendidas entre 19 y 40 años, que tenían por lo menos um (a) hermano (a),
Recebido em: 20/04/2015

Revisado em: 20/05/2015

Aceito em: 29/06/2015 
adoptado (a). Las entrevistas fueran analizadas según la técnica de análisis de contenido. Se observó, sobre todo al principio, sentimientos ambivalentes y fueron necesarios reajustes en la família para la inserción del nuevo miembro, pero la convivencia fundamentó la relación entre los hermanos. La gran diferencia de edad entre algunos hermanos levó el hijo biológico a comportarse como hermano paterno. El tratamiento dado por los padres a sus ninos ya existentes, así como la preparación de estos eran esenciales para la aceptación del niño adoptado. Se puede concluir que, en la maioria de los casos, no se percebe diferencia em la fratria por médio de consanguinidad o adoption, como son los vínculos emocionales entre padres y hijos que determinam y movilizan tanto rivalidades como fraternidades.

Palabras clave: adopción; hermanos; padres; relación fraternal.

\section{Résumé}

Cette recherche se donne pour but de mieux comprendre les perceptions et expériences résultant de l'arrivée d'un enfant adoptif dans la famille. Pour ce faire, ont été interviewés sept adultes, de 19 à 40 ans, qui avaient au moins un frère ou sæur adopté(e). Les entretiens ont été analysés selon la technique d'analyse de contenus. Une ambivalence de sentiments fut observée, principalement au début, la famille devant passer par un réaménagement pour que le nouveau membre puisse s'y insérer, mais la vie commune a finit par renforcer les relations fraternelles. Une importante différence d'âge, dans le cas de certains frères, a conduit le fils biologique à se conduire comme un frère parental. La façon des parents de traiter leurs enfants biologiques, ainsi que la préparation de ces derniers au moment de l'adoption, ont été essentielles pour que l'enfant adopté soit accepté. Nous pouvons conclure que, dans la majorité des cas, nous n'avons pas observé de différences notoires entre les fratries consanguines ou adoptives, car c'étaient les liens affectifs tissés entre les parents et les enfants qui déterminaient et mobilisaient les rivalités et les relations fraternelles.

Mots-clés: adoption; fratrie; parents; relations fraternelles.

O sentimento de fraternidade é sempre colocado como um ideal a ser atingido pelos povos, mostrando que cada um deve suprassumir e sublimar as rivalidades fraternas em sentimentos de solidariedade e companheirismo, razão pela qual o substantivo "fraternidade" conota sempre um sentido positivo - com apelo ao amor e à união entre irmãos. Freud, em "O mal-estar na civilização" (19291930/1980), realça que a civilização impõe ao sujeito certas renuncias pulsionais para que a convivência com os outros seja possível. Os ódios e as rivalidades vividas entre os semelhantes precisam ser sublimados para que haja paz. Mesmo assim, a história testemunha que nem sempre é possível conter e transformar tais sentimentos, o que causa os conflitos e as guerras.

No que se refere à literatura em Psicologia e em Psicanálise sempre se deu ênfase às relações pais e filhos, ficando os vínculos fraternos em segundo plano, não por serem desconsiderados como fazendo parte da subjetividade, mas porque a formação das fratrias e seus vínculos afetivos estão submetidos à lei do pai. Isso significa que o modo como cada um acolhe e inscreve seu irmão na história familiar depende de como ele próprio foi acolhido no seio da família. Se os pais são capazes de dar um lugar para cada filho nas suas cadeias simbólicas, isso implica que a chegada de um novo membro não representará a perda de seu lugar junto aos pais. Mesmo assim, isso mobilizará mudanças de posição e ajustes na economia pulsional da família. Enquanto isso, ciúmes, inseguranças e ódios são vividos, declarada ou disfarçadamente, entre os irmãos, cabendo aos pais administrá-los.

Em tempos cuja tônica é falar da falência paterna, ou seja, de que a lei do pai não tem o mesmo vigor e função ordenadora de antes - com a prevalência das relações horizontais, em detrimento das relações verticais, e a existência de diferentes arranjos familiares, que não seguem a mesma organização da família nuclear - a questão das fratrias passou a ser objeto de interesse e de pesquisas. A exemplo temos os estudos de Amaral e Dias (2012), Oliveira (2005), Paulo (2006), Pereira e Arpini (2012), quando discutem as famílias recasadas; Crespo (2013) e Dellazzana e Freitas (2010), ao refletir sobre as relações de cuidado entre irmãos; Gomes e Bosa (2004), Nunes e Aiello (2007), Souza, Franco, e Carvalho (2009), tratando das fratrias em que um dos irmãos apresenta algum tipo de necessidade especial.

A legislação brasileira reconhece a importância da manutenção desse vínculo e, no caso de adoção, os grupos de irmãos devem ser colocados sob a tutela ou guarda de uma mesma família substituta, de modo a evitar o rompimento de tal vínculo (Estatuto da Criança e do Adolescente [ECA], Art.28, 1990). Neste caso fica garantida a manutenção do vínculo entre irmãos consanguíneos.

No que se refere às famílias constituídas por filhos consanguíneos e não consanguíneos, denominadas como famílias mistas, o tema da irmandade apresenta-se de extrema importância, ao permitir se averiguar os sentimentos mobilizados diante da chegada de um irmão adotivo. Como nos ensina Lacan (1977), o irmão é sempre um intruso e, segundo ele, o complexo de intrusão representa a experiência de todo sujeito quando vê seus semelhantes participarem, junto com ele, da relação doméstica. Daí a questão que se coloca: o fato de ser um irmão não consanguíneo despertaria sentimentos de maior estranhamento e rivalidade que entre os irmãos consanguíneos? Afinal, durante muito tempo, a legislação discriminou os filhos consanguíneos, do adotivo, no que se refere à herança e outros direitos. 
Nessa perspectiva, foi desenvolvida uma pesquisa com o objetivo de analisar as percepções e as experiências de filhos consanguíneos com a chegada de um (a) irmão (ã) adotivo (a) na família. Foram entrevistados sete jovens adultos (seis mulheres e um homem), filhos biológicos, na faixa etária entre 19 e 40 anos, que possuíam irmãos adotivos. Eles foram adotados ainda bebês, com exceção de um que foi adotado com quatro anos de idade.

\section{O Vínculo Fraterno}

A entrada do irmão na família (seja ele consanguíneo ou adotivo) abre espaço para a alteridade, para a constatação do papel que cada um tem no grupo familiar, mas também para uma infinidade de combinações subjetivas que se abrem ante a descoberta da semelhança na diferença (Paulo, 2006). Segundo Meynckens-Fourez (2000, p. 20), "a fratria poderia ser vista como um conjunto de vasos comunicantes. O movimento de um tem repercussões sobre o outro, o comportamento de um influencia a resposta do outro". A fratria possibilita viver um ensaio da vida social (Brazelton \& Sparrow, 2007; Britto, 2002; Meynckens-Fourez, 2000; Rufo, 2003).

$\mathrm{O}$ vínculo fraterno tem características próprias: se de um lado mobiliza pulsões agressivas, sentimentos de abandono, ciúmes e rivalidades, por outro mobiliza seduções (conotando tanto a capacidade de persuadir e convencer, como o jogo amoroso e, muitas vezes, incestuoso, que caracterizam as relações entre irmãos) e identificações mais duradouras, pois os indivíduos permanecem mais tempo como irmãos do que como filhos. Os irmãos geralmente compartilham as diferentes fases do ciclo vital, o que não ocorre com outros relacionamentos também importantes como amigos e cônjuges (Braungart, Plomin, DeFries, \& Fulker, 1992; Silveira, 2002).

Nos casos em que um ou ambos os pais falham nas suas funções parentais, ou em que ocorre a morte ou separação entre eles, os vínculos entre os irmãos podem ser mais fortes do que com os próprios pais. Por outro lado, os vínculos fraternos também estão mais expostos a rupturas e distanciamento. Desse modo, a distância geográfica e a falta de convivência aparecem como dificultadoras do relacionamento entre irmãos. Para Eiguer (2012, p. 145) "a coabitação possibilita o vínculo de afiliação entre os membros da família, contribuindo para reforçar os novos apegos e a inserção de pessoas no parentesco e na genealogia".

Fatores como sexo, idade, posição na ordem de nascimento, temperamento da criança, bem como o posicionamento dos pais diante dos filhos também atravessam a relação entre os irmãos (Goldsmid \& FéresCarneiro, 2007). Meynckens-Fourez (2000) acrescenta ainda o tamanho da fratria. Essa autora refere que naquela composta apenas por dois irmãos a rivalidade tende a ser mais exacerbada, pois falta um terceiro para mediar e atenuar a tensão existente na díade. Já nas fratrias numerosas, a rivalidade fica mais diluída no que se refere ao desejo de exclusividade junto aos pais, uma vez que eles têm que distribuir a atenção entre vários filhos.

O evento "tornar-se irmão" é uma experiência peculiar para a criança que até então era apenas filho, é uma tarefa que exige reorganizações presentes e futuras. Mesmo quando há uma preparação, por parte dos pais, para a nova situação, é a vez de os primogênitos - ou dos filhos já existentes - se organizarem e também se prepararem para a recepção e a acolhida. A delicadeza dessa situação reside na ambivalência que a criança vivencia. Satisfação e medo são sentimentos que ela experimenta nos meses de espera e algum tempo logo após o nascimento. A criança recém-chegada vai transformar o (s) filho (s) existente (s) em irmão (s) mais velho (s). Automaticamente ele (s) receberá (ão) um título que será inversamente proporcional às atenções antes a ele (s) dispensadas, o que o (s) ajudará a desenvolver um pouco de independência e autonomia (Paulo, 2006; Silveira, 2002).

Por outro lado, fantasias de incapacidade no cumprimento do seu papel de filho se alternam com o desejo de conhecer face a face o irmão. Assim, é como se o desejo parental de ter outro filho fosse uma forma de dizer à criança que ela não é boa o bastante para realizá-los como pais. Numa época em que a criança constrói sua autoestima a partir do olhar que ela recebe ou imagina receber de seus pais, essa questão pode ter um efeito devastador (Paulo, 2006). Todos esses fenômenos configuram uma fase que é caracterizada como adaptação.

O relacionamento fraterno começa quando um irmão mais velho toma a consciência da existência do outro (Oliveira, 2005). Esse fato pode ser a gravidez (de sua mãe ou da esposa do seu pai, nos casos de famílias recasadas), ou a confirmação que uma criança será dada em adoção para a família. A figura dos irmãos na adoção merece destaque, pois a literatura sobre esse tema tem focalizado mais os pais e a própria criança adotada. A presente pesquisa, portanto, teve como objetivos investigar as percepções e as vivências de filhos biológicos diante da chegada de um adotivo na família.

\section{Peculiaridades da Fratria Adotiva}

A fratria formada pela adoção se caracteriza a partir da falta dos laços biológicos e da construção de vínculos afetivos propiciada pela convivência (Schettini Filho, 1999). Tomamos as palavras laço e vínculo como formas diferentes de ligação. Apesar de muitas vezes serem usadas como sinônimos, a primeira será utilizada para fazer alusão à consanguinidade e a segunda para falar da construção 
psíquica comum, a partir do convívio. A fratria formada pela adoção de crianças maiores se caracteriza pela falta da convivência, na família adotiva, desde a tenra infância. Muitas dessas crianças já constituíram fratrias com irmãos biológicos e, nesse novo contexto, precisarão construir vínculos afetivos com os novos pais e irmãos. A adaptação da criança aos novos pais e irmãos requer grande esforço de todos, propiciando à criança adotada um verdadeiro "renascimento" psicológico (Rufo, 2003). Para Otuka, Scorsolini-Comin, e Santos (2012), a adaptação à família adotiva solidifica o sentimento de inclusão e pertencimento no filho adotivo, o que contribui para atenuar o trauma do rompimento dos laços com a família de origem.

Braungart et al. (1992) referem que irmãos biológicos separados e adotados por casais diferentes, ao se reencontrarem na vida adulta, sentem-se como estranhos. Em contrapartida, quando grupos de irmãos são separados, mas continuam a manter contato, o vínculo permanece. Os autores afirmam que o vínculo depende do contato, caracterizando-se como uma conquista diária e uma decisão, no sentido de que os envolvidos na relação desejam nela permanecer. Maldonado (2006) também concorda que o vínculo é uma decisão. Ao se referir à adoção, ela defende que filhos biológicos e adotivos devem ser inscritos no coração e na alma dos pais. Schettini Filho (1999) diz que todos os filhos são biológicos e adotados simultaneamente: biológicos porque esta é a única forma de um ser humano ser gerado e vir ao mundo; adotados porque é preciso que os pais disponibilizem para a criança a capacidade de se sentir pertencente e acolhida física e psicologicamente por um grupo.

Segundo Carvalho e Bussab (2013), o desenvolvimento individual não é um processo determinado e previsível, portanto, o ajustamento da criança adotiva à família pode variar dependendo de diversos fatores como: idade por ocasião da adoção, condições de experiência institucional, características individuais dos envolvidos e marcas que ficaram da vida pregressa. Para as referidas autoras, quanto mais cedo se realizar a adoção, menos exposta a criança estará à institucionalização e menos sequelas ela apresentará. Elas também pontuam que diferentes figuras de apego podem oferecer contribuições variadas para a criança.

Na fratria nem tudo são rosas: há competições, brigas, disputas, ciúmes, mas também momentos de diversão, cumplicidade e de cuidado mútuo. Os irmãos alternam comportamentos denominados como positivos (brincar juntos, proteger, confrontar, orientar) e negativos (brigar, ignorar, disputar, hostilizar), a depender das situações em que estão inseridos. E mesmo que o relacionamento entre eles seja difícil, não se pode afirmar que não haja ligação (Britto, 2002; Oliveira, 2005; Paulo, 2006).

A ambivalência na fratria adotiva é tão comum e saudável quanto na biológica. $\mathrm{O}$ indicativo de que há algo de errado é quando a fase de 'lua de mel' entre os irmãos e a criança recém-chegada perdura por muito tempo. O comum e o esperado, passada a fase de adaptação, é que os conflitos passem a acontecer. Quando eles não ocorrem, a fratria pode estar vivenciando uma patologia na capacidade de vinculação. É o que Pichon-Rivière (2000) chamou de 'indiferença'.

Para que o indivíduo vivencie um vínculo saudável é preciso que se sinta diferenciado. Nos casos de adoção de crianças maiores, talvez por temor a um novo abandono, a criança que acabou de chegar sinta tanta vontade de ser aceita que a identificação com os irmãos pode suplantar o seu modo real de ser. Ela passa a copiar os irmãos, com tudo concorda, sendo sempre a boazinha e, de tão identificada com eles, não se diferencia. Mas a falha na vinculação pode ocorrer de outra forma. Se as primeiras experiências na família de origem não foram vividas de forma saudável, como nas situações de abusos, violências e negligências, a criança pode abster-se de interagir com a nova família, ou fazê-lo com desconfiança.

Ainda em Pichon-Rivière (2000) encontra-se o fenômeno da 'despersonalização', que consiste na tentativa de o indivíduo de se fazer passar por ninguém, para que não tenha que assumir um compromisso vincular com o outro. A fratria, nesses casos, tem um papel crucial, pois, observando como os irmãos se relacionam uns com os outros e com os pais, a criança recém-chegada poderá dar um novo significado ao que venha a ser vida em família.

\section{Método}

\section{Participantes}

Os participantes foram sete jovens adultos e adultos (seis mulheres e um homem), filhos biológicos, com idade entre 19 e 40 anos. Eles foram selecionados a partir do fato de possuir irmãos adotivos. Todos os adotados, à época da adoção, eram bebês, com exceção do irmão de Raquel, que tinha quatro anos, configurando a denominada adoção tardia ou de criança maior. No caso em que havia mais de um adotivo na família o (a) participante se referiu à primeira adoção. Para preservar sua identidade, eles receberam nomes fictícios. Na Tabela 1 são descritos os dados sociodemográficos dos participantes:

\section{Instrumento}

Foi utilizado um roteiro de entrevista, composto de dez questões relacionadas aos objetivos da pesquisa, tais como: reação diante da chegada do adotivo; as mudanças que ocorreram na sua vida a partir desse momento; o tratamento dispensado pelos pais ao filho, antes e após a 
Tabela 1

Dados sociodemográficos dos participantes

\begin{tabular}{lcllcc}
\hline \multicolumn{1}{c}{ Nome } & Idade & Estado Civil & \multicolumn{1}{c}{ Profissão } & $\begin{array}{c}\text { Irmãos } \\
\text { Biológicos }\end{array}$ & Irmãos Adotivos \\
\hline Ana & 19 & Solteira & Estudante universitária & 1 & 1 (1 ano e 8 meses $)$ \\
Izabel & 36 & Casada & Policial civil & 3 & 1 (21 anos) \\
Maria & 34 & Casada & Dona de casa & 14 & 2 (20 e 4 anos $)$ \\
Moisés & 25 & Solteiro & Técnico em informática & 1 & 1 (22 anos $)$ \\
Raquel & 20 & Solteira & Estudante universitária & 0 & 1 (24 anos $)$ \\
Rebeca & 38 & Desquitada & Professora & 1 & $1(24$ anos $)$ \\
Rute & 40 & Casada & Comerciária & 2 & $1(32$ anos $)$ \\
\hline
\end{tabular}

chegada do (a) irmão (ã); os sentimentos experimentados em relação a esse (a) irmão (ã). A entrevista foi conduzida de forma semidirigida. Também foram preenchidos os dados sociodemográficos dos participantes.

\section{Procedimento de Coleta de Dados}

Inicialmente o projeto de pesquisa foi aprovado pelo Comitê de Ética, da instituição que apoiou a pesquisa, sob o número $095 / 2007$. O recrutamento dos participantes foi feito por meio de um site de relacionamentos no qual identificamos pessoas que fazem parte de comunidades relacionadas à temática da adoção. Eles foram contatados virtualmente e, posteriormente, entrevistados, pessoal e individualmente, na sua própria residência ou em locais que lhes eram convenientes. Foi explicado a cada participante o objetivo da pesquisa e solicitada a assinatura do Termo de Consentimento Livre e Esclarecido, conforme determina o Comitê de Ética. As entrevistas foram gravadas e depois transcritas.

\section{Procedimento de Análise de Dados}

Foi utilizada a análise do conteúdo, considerando três etapas: (a) pré-análise, que é composta pela leitura flutuante, ou seja, o pesquisador deixa-se impregnar pelo conteúdo, por meio de exaustivo contato com o material, para constituir o corpus e formular algumas hipóteses de trabalho; (b) exploração do material, que consiste em separar as categorias ou eixos temáticos, a serem discutidos adiante; (c) análise e interpretação dos resultados, com base na literatura consultada (Minayo, 2004).

\section{Resultados e Discussão}

Para realizar a análise, as respostas foram categorizadas em cinco eixos temáticos: (a) a preparação da chegada do irmão adotivo; (b) a reação da família diante da chegada do novo membro; (c) o tratamento recebido dos pais pelo filho antes e após a chegada do irmão adotivo; (d) o tratamento dispensado pelo participante ao irmão adotivo; (e) os sentimentos experimentados.

Preparação para a chegada do (a) irmão (ã) adotivo (a)

Segundo Brazelton e Sparrow (2007), é preciso que os filhos existentes, antes da adoção de uma criança, tomem conhecimento da decisão do casal, ficando claro que tal decisão compete aos pais. É preciso dar espaço para que eles possam compartilhar seus sentimentos, do contrário a adoção pode ser sentida como uma invasão, sobretudo porque, diferente da chegada de um irmão via processo gestacional, em que há uma adaptação paulatina propiciada pelos meses de espera pelo nascimento, nem sempre isso acontece com a chegada do irmão adotivo, que pode ocorrer a qualquer momento. Por outro lado, alguns pais, para não criar falsas esperanças, preferem só falar da chegada do filho quando a criança está disponibilizada para adoção, o que gera um descompasso entre a espera dos pais e a não espera dos irmãos. E quando a criança chega, isso pode configurar uma invasão para os irmãos. A preparação da fratria para a chegada de um novo irmão tem um caráter profilático, pois adaptar-se a uma nova realidade torna-se mais fácil quando se tem um conhecimento prévio sobre ela e, consequentemente, facilitará a construção dos novos vínculos.

No caso da pesquisa em pauta nem todos os entrevistados foram preparados para a chegada do irmão adotivo; uma delas não lembrou como se deu por ser muito nova. Seguem alguns comentários dos entrevistados:

(...) eu já sabia que ia ganhar um irmão ou uma irmã, 
porque mesmo de longe minha mãe ajudou na gravidez dela. Todos lá em casa sabiam que uma criança ia chegar de uma hora pra outra... (Maria)

Não fui preparado não. Foi meio de surpresa. Sei que foi uma ideia da minha mãe, daí aconteceu. Minha mãe adotou meu irmão uns dois anos depois do meu nascimento. Eu não lembro muito de detalhes da chegada dele (Moisés).

Como sempre gostei muito de crianças, em especial bebês, sempre fui louca pra ter um irmãozinho. Queria um menino, pois já tenho uma irmã mais velha. Então foi maravilhoso. Como a maioria das decisões tomadas na minha família, esta só foi decidida com aprovação de todos. Foram levantados prós e contra. Eu levantei alguns, mas os prós sempre excediam os contras. (Ana)

Os trechos relatados indicam uma atitude positiva e de expectativa mesmo quando, sem preparação, os conflitos e problemas apareceram com a chegada do novo membro.

\section{Reação da Família Diante da Chegada do Novo Membro}

Conforme as falas dos participantes, a reação foi positiva, ainda que alguns tenham referido que a chegada de um novo irmão gerou a necessidade de uma reorganização nos papéis até então desempenhados por cada integrante do sistema familiar. Isso também ocorre por ocasião da chegada de um filho biológico e tal desequilíbrio é facilmente perceptível nos conflitos que surgem decorrentes da redistribuição das tarefas (Pereira \& Piccinini, 2007). Sobre isso corrobora a fala de Rute:

Lá em casa os meus pais adoraram. Começaram tudo de novo. Foi uma nova experiência pra todo mundo. Pra mim já foi um pouco difícil. 'F' era muito novo, muito bebê. Tinha muita confusão entre mim e ' $\mathrm{C}$ ' [irmão mais velho] para ver quem cuidava dele. Com o tempo, as coisas foram se normalizando.

Asseveramos que, desde a gravidez, as mudanças nos relacionamentos entre pais e filhos ocorrem, quando a família começa a se reorganizar, antecipadamente, em busca de um novo equilíbrio, concordando com Pereira e Piccinini (2007). Considerando a filiação por adoção, acrescentamos que o relacionamento e a reorganização começam a se dar desde a época em que são iniciadas as conjeturas da adoção, ficando mais intensos com a entrada legal no processo. Dois relatos mostram a alegria com que a criança foi recebida:

Essa criança foi ansiosamente esperada desde que eu nasci e minha mãe ficou sem poder engravidar. Como ela era a concretização de um sonho, nós reagimos muito bem, tanto eu quanto minha outra irmã. (...) Todo mundo queria ela no colo, era uma guerra. Ela não foi um bebê muito tranquilo, tinha refluxo, daí a gente se revezar com ela sempre no colo. (Rebeca).

Meus pais ficaram muito alegres. Eu já tinha 15 anos. Era um bebê dentro de casa. (...) Ela era uma prenda... Uma bonequinha... Penteá-la, cuidar dela foi tão bom... Todos nós ficamos muito felizes. (Isabel)

Nesses dois casos, existe uma considerável diferença de idade entre a criança adotada e a fratria já constituída. Observamos aqui uma particularidade que é quando o (a) irmão (ã) mais velho (a) assume também cuidar do bebê; nesse caso, ele (ela) pode se sentir e perceber mais pai (mãe) que irmão (irmã). Autores utilizam a terminologia 'irmão parental' (Brazelton \& Sparrow, 2007; Britto, 2002; Oliveira, 2005). Rufo (2003), por sua vez, usa a nomenclatura 'pais pequenos'. Nessas situações, as fronteiras entre os diversos membros da família ficam difusas, mas Pereira e Piccinini (2007) defendem que os subsistemas e os papéis de cada um devem ser preservados, para que ocorra a diminuição de conflitos, que podem dificultar o sucesso na formação do subsistema fraterno. Esses conflitos foram denominados como 'intrageracionais' (Goldsmid \& Féres-Carneiro, 2007). Sempre é bom lembrar que subjacente ao desejo dos filhos de cuidar estão implicados dois sentimentos: o de rivalizar com os pais, pois pela diferença de idade a vez agora seria a deles de serem pais; e o de manter a fratria inalterada, pois o irmão temporão, adotivo ou não, ocupará outro lugar, ou seja, mais de filho dos irmãos e neto dos pais.

Em contrapartida, quando a adoção é concretizada quando os irmãos ainda são crianças, a construção do vínculo fraterno acontece da mesma forma que ocorre com uma fratria biológica. Brazelton e Sparrow (2007) apontam que a proximidade cronológica e de convivência permite um maior entrosamento e identificação entre os integrantes da fratria, uma vez que crescem dividindo vivências comuns e os vínculos podem ser estabelecidos de forma mais igualitária. No entanto, convém considerar, nos excertos relatados acima, a presença do desejo materno na decisão de adotar, o que levou os irmãos a manifestarem sentimentos concordantes com os dos pais para continuar a serem aceitos e a não perder seus lugares.

\section{Tratamento Recebido dos Pais pelo Filho Antes e Após a Chegada do (a) Adotivo (a)}

Nesse tópico se faz necessário pontuar as diferenças encontradas entre os participantes que já faziam parte de um subsistema fraterno e uma que teve a fratria inaugurada com a chegada do irmão adotivo. König (1995) refere que as expectativas dos pais variam para cada filho, de acordo com a ordem de nascimento e, no caso da adoção, elas sofrem influência da ordem de chegada da criança à 
família. Brazelton e Sparrow (2007), por sua vez, pontuam que o tratamento que o adotado vai receber por parte do (s) irmão (s) está relacionado, principalmente, à interação, às motivações e ao posicionamento dos pais diante do filho adotado.

No caso de Raquel, ela ainda era um bebê quando seu irmão adotivo foi inserido na família, com quatro anos de idade. Dessa forma, ele se tornou o mais velho. Nesse caso ocorreu uma perda de lugar vivida com ressentimento. Ainda hoje esse ressentimento aparece; também ela deseja e sente ciúmes dos cuidados e da atenção que o pai direciona ao irmão adotivo, percebendo-o como privilegiado. Tudo leva a crer, embora isso não esteja explícito nos depoimentos de Raquel, que a preferência dos pais era por um filho homem, pois, mesmo com uma criança pequena em casa, buscaram a adoção de um menino. Vejamos sua fala:

Como eu era pequena não lembro, mas acredito que devem ter me tratado bem. Eu era um bebê também, precisava tanto de cuidados como ele. (...) Hoje meus pais (mais meu pai) deixam muito a desejar (...) o melhor curso é dele, a melhor regalia é a dele... (Raquel)

Outro participante percebeu a chegada do irmão adotivo como negativa, alegando ter perdido o espaço e as atenções que recebia antes, o que comprova que a qualidade da relação entre os pais e os filhos existentes é fundamental para a aceitação do novo irmão:

Antes eu era bem paparicado mesmo. Minha mãe é mais chegada a ele do que a nós dois [referindo-se a ele e à irmã biológica]. Meu pai gosta da gente sem separar, sem distinguir. (Moisés)

Brazelton e Sparrow (2007) denotam que os pais são afetados pelos filhos de forma diferente, sejam eles biológicos ou adotivos. Eles podem então partir para compensar as diferenças sentidas em relação aos filhos biológicos e adotivos. Segundo os autores: "pais adotivos que têm filhos biológicos podem descobrir que nutrem sentimentos diferentes em relação aos filhos biológicos e ao adotivo" (p. 74). Portanto, é necessário encarar esses sentimentos com honestidade, em vez de reprimi-los, uma vez que as crianças percebem as tentativas dos pais para compensar esses sentimentos. O que os referidos casos têm em comum é o fato de que tanto Raquel como Moisés eram bebês que ainda necessitavam de atenção quando o irmão adotivo foi inserido na família.

Segundo Britto (2002), irmãos mais velhos receberão cobranças diferentes e, às vezes mais intensas, pois são os primeiros depositários das expectativas, ansiedades e insegurança dos pais. A chegada do primeiro filho inaugura uma família e cria as funções de pai e mãe, diferente do que acontece com a chegada dos demais filhos que encontram um contexto familiar já estabelecido. Mesmo assim, cada filho tem uma imagem distinta da família, pois todo o grupo é alterado e reordenado com a entrada de um novo membro. Novos investimentos pulsionais são mobilizados: (a) os mais velhos precisarão desenvolver a competência de compartilhar, a despeito da rivalidade sentida; (b) os pais cuidarão dos filhos, acolhendo suas demandas conforme suas singularidades (Britto, 2002). Na perspectiva dos filhos, nunca há pais suficientes, pois cada um exige deles uma atenção especial. Segundo a autora, a maneira como os pais lidam com os desejos dos filhos e redistribuem as cargas pulsionais, acatando-as ou reprimindo-as, determinará a relação entre os irmãos. Os depoimentos abaixo ilustram situações positivas no que diz respeito à economia psíquica.

As coisas não mudaram muito pro meu lado. Continuei no mesmo colégio, fazendo as mesmas coisas, só que agora eu era um irmão mais velho... (Moisés)

No início, foi confuso porque eu era uma mocinha, tudo é uma adaptação. No mais, a minha experiência como irmã adotiva deixou mais impressões boas do que ruins, ' $\mathrm{F}$ ' trouxe mais amor pra casa, mais compreensão, pois a gente teve que aprender a superar novos problemas (...). (Rute)

Nos casos em que já existia uma fratria constituída (cinco) percebemos que a aceitação e o acolhimento ao irmão adotivo se processaram de maneira mais fácil, pois a experiência de compartilhar já estava instalada. No entanto, isso não significa que sentimentos de rivalidade estejam ausentes, como bem expressam as falas dos participantes a seguir:

Assim que ela chegou não mudou nada. Depois de algum tempo ela passou a receber mais atenção, lógico era um bebê! Hoje eu sou mãe e entendo, mas na época não gostava muito não... Eu já tinha perdido minha mãe, e depois meu pai... Se não fosse meus irmãos... Mas hoje passou. Sou mais irmã dela que dos outros (...). (Isabel)

Eu deixei de ser a caçulinha da família. Sempre me trataram com respeito, amor e atenção. A atenção, porém, diminuiu, pois um bebê precisa de mais cuidados do que um adulto como eu. (Ana)

Meus pais estavam mais felizes e tratou todos nós melhor. Eu saí de meu emprego para cuidar dela. Eu tinha 13 anos. Minha mãe trabalhava e meus irmãos também. Eu fiquei com a ' $\mathrm{L}$ '. A tristeza da casa diminuiu, mas as minhas responsabilidades aumentaram. Lá em casa os mais velhos cuidavam dos mais novos. A responsabilidade era dividida assim: o pai e a mãe tinham que 'tá no roçado' e a gente que se virava... (Maria) 
Acredito que o sentimento deles pra mim não mudou com a chegada de ' $\mathrm{F}$ '. A gente continuou recebendo amor e limites. O que mudou de verdade foi que a gente ficou mais preso, pois com um bebê não se passeia tanto nem se vai pros mesmos lugares que se passeia com filhos maiores. (Rute)

James, Monn, Palinkas, e Leslie (2008) afirmam que a forma como a fratria se relaciona é reflexo de como a família inteira interage, pois, na maioria dos casos, são os pais que passam a visão do que venha a ser uma fratria para seus filhos, através de palavras ou atitudes. Muitas vezes, essa visão é uma reedição da vivência deles próprios enquanto irmãos. Predileções claras ou camufladas por parte dos pais, o estímulo ou não às disputas, os espaços subjetivos e físicos mal divididos podem prejudicar o desenvolvimento da habilidade de estabelecer e manter o relacionamento fraterno. No relato de Maria, por exemplo, a chegada do irmão significou uma sobrecarga para ela que teve que abrir mão de suas atividades para cuidar dele.

\section{Tratamento Dispensado pelo Participante ao (à) Irmão} (ã) Adotivo (a)

A maioria dos irmãos rememorou a experiência da chegada de seu irmão ou irmã adotivo (a) com alegria, facilmente perceptível nas expressões faciais e nas verbalizações:

Ela era uma bonequinha... Penteá-la, brincar com ela foi tão bom (...). Hoje em dia por causa disso penso em adotar uma criança. Já tenho dois filhos, mas penso em adotar (...) (Isabel)

Todo mundo queria ela no colo, era uma guerra (...). Ela ficou um dengo só! (Rebeca)

Mesmo antes da chegada da criança, os irmãos que já existem na família experimentam inveja, ciúme, rivalidade bem como cumplicidade, companheirismo e solidariedade (Perez, 2002). Para a autora, o esperado é que os sentimentos entre irmãos evoluam para um estágio de ajuda mútua e de cooperação apesar de que, em alguns casos, inveja e ciúme sempre existirão. No nosso entender, os sentimentos hostis podem ser sublimados em sentimentos saudáveis de competitividade que lhes serão úteis nas relações sociais futuras. Para que isso aconteça, a forma como os pais lidam com as rivalidades fraternas será decisiva.

Porém, em lugar da hostilidade ou companheirismo pudemos verificar a indiferença expressa na seguinte frase: "Somos muito diferentes. Nosso relacionamento é sem conflitos, morno, sem aquele amor de irmão" (Raquel).

Conforme fora referido por Pichon-Riviére (2000), quando ocorre um nível intenso de apatia entre os irmãos, pode estar sendo vivenciada uma patologia. Tomando como base as pontuações de Goldsmid e Feres-Carneiro (2007), tudo indica que não houve sucesso na construção psíquica comum, ou seja, o vínculo.

No caso de Raquel houve uma subversão de lugares, ou seja, quem nasceu primeiro foi usurpada do seu lugar com a chegada de um irmão de quatro anos. Ele era mais velho, mas não o mais antigo, subvertendo a ordem natural das fratrias. Sendo o mais velho, o irmão adotivo assumiu a posição de liderança.

\section{Sentimentos Experimentados para com o (a) Irmão (ã) Adotivo (a)}

A fratria é marcada por uma gama de sentimentos que normalmente podem transitar da rivalidade para a solidariedade. Esses sentimentos, aliados a uma realidade de estreita convivência que estimula a intimidade, proporcionam que essa díade se transforme num lugar subjetivo que pode ser equiparado a um território seguro, cujos integrantes se sentem livres para compartilhar segredos, sonhos, dores, alegrias, ansiedades. Mas também há os casos, como indica Britto (2002), em que esse espaço subjetivo é semelhante a um campo minado e a rivalidade fraterna se cronifica, dificultando que os irmãos desenvolvam uma relação de companheirismo e de cordialidade reais.

Raspantinni e Escrivão (2003) asseveram que a adoção se fundamenta na premissa de que a integração da criança à nova família possibilita a construção (ou reconstrução em casos de adoção de crianças maiores) da identidade, a partir de um relacionamento satisfatório com os pais. Quando os autores se referem a satisfatórios não descartam a possibilidade de que as dificuldades dos filhos, ocasionadas pelas disputas pelo amor e atenção por parte dos pais, gerem conflitos. Tomando como base as respostas obtidas, levantamos a suposição de que, quando as dificuldades entre irmãos não são solucionadas na infância, elas podem assumir a feição de distanciamento e conflitos na fase adulta.

Nossos pais e avós costumavam dizer: "irmãos que brigam muito quando crianças são unidos quando adultos". Sem fazer disso uma regra, significa que eles conseguiram, quando jovens, descarregar suas pulsões agressivas, mas como já realçamos anteriormente, a transformação dos sentimentos hostis em companheirismo e solidariedade vai depender de como os pais interferem nos conflitos. Os pais precisam ser firmes, colocar limites quando a hostilidade extrapola os limites do aceitável, saber reconhecer as diferenças sem tomar partido Essas são algumas atitudes facilitadoras. As preferências são perniciosas tanto para o preterido, quanto para o preferido que pode carregar o ônus dos castigos impostos ao irmão ou manter-se indiferente a ele como observamos no exemplo abaixo. 
Não sei se gostava dele não. Ficava com ciúme. Quando a gente era pequeno, eu fazia as coisas e colocava a culpa nele. Ele meio que tirou meu lugar (...). Hoje a gente se fala, mas não somos muito amigos. Minha mãe o protege demais. Achamos [ele e a irmã biológica] que ele tem problemas com drogas. Ele não liga muito para o que a gente fala não. Minha irmã já deixou de mão, eu vou fazer isso também. (Moisés)

Os irmãos tendem a se organizar em pares emocionalmente significativos. A identificação não é a mesma para com todos os irmãos, e isso nada tem de patológico. Os conflitos podem ser manifestados sob a forma de alianças, um modelo relacional que pode esconder rivalidades. Mas as alianças podem evoluir para as coalizões, quando dois membros se unem contra um terceiro, prejudicando a aproximação entre uns e estimulando conflitos entre outros (Oliveira, 2005). Na fala do participante Moisés, ficou evidente uma coalizão que consiste na aliança dos irmãos biológicos e na exclusão do adotivo, provavelmente fruto da superproteção materna ao adotivo: “(...) como minha mãe protege sempre ele, eu e minha irmã tivemos que nos proteger..."

Todavia, também existem união, solidariedade e cumplicidade entre os irmãos. O vínculo entre eles pode desempenhar importante papel no equilíbrio familiar, especialmente nos momentos de crise ou mudança na estrutura da fratria como é o caso de recasamento, divórcio, adoecimento ou morte na família (Goldsmid \& FéresCarneiro, 2011; Meynckens-Fourez, 2000). A fala de Rebeca exemplifica o que foi dito:

Apesar de muito mimo, ela é uma pessoa ajuizada. Sempre deu muito gosto. Já é formada. Ela é mais próxima a mim do que minha irmã biológica, que é uma pessoa difícil. Mora em outro estado e é meio alheia. Eu contei muito com a ajuda da mais nova para cuidar de minha mãe. Ficamos juntas até nossa mãe morrer. Já minha irmã mais velha, como eu disse, não se envolvia muito. (Rebeca)

$\mathrm{Na}$ idade adulta, o envolvimento na vida profissional e nas responsabilidades com a própria família pode deixar os irmãos mais distantes. Quando a dinâmica da família de origem estimulou a cooperação e a solidariedade, os irmãos tendem a apoiar-se e fortalecer-se por ocasião da velhice dos pais (Goldsmid \& Féres-Carneiro, 2007; Oliveira, 2005). Mesmo quando ocorre o distanciamento geográfico e pouco tempo de interação contínua, isso não caracteriza a inviabilidade do relacionamento. Percebemos que as fratrias constituídas por adoção seguem o mesmo movimento, como mostra Isabel:

Hoje ela tem 21 anos, mora em N. e já está trabalhando. Hoje eu me dou muito bem com ela. Melhor até que com meus irmãos biológicos. $\mathrm{O}$ mais velho mora em $\mathrm{N}$, mas quase nunca eu o vejo; o mais novo 'deu pro mundo', usa drogas, olha, é um trabalho! Minha outra irmã já é avó e está envolvida com seus dois empregos, filhos e netos. Só com minha irmã adotiva é que tenho mais contato, que ironia não é? Tá vendo, isso mostra que o sangue é só um detalhe!

$\mathrm{Na}$ maioria dos depoimentos, a ausência da consanguinidade não foi referida como um fator que dificultou a relação entre os irmãos. Uma participante tem duas irmãs adotivas e duas delas, além de terem vivenciado a adoção na fratria, vivenciam-na hoje como mães, o que indica que a experiência como irmãs por adoção foi positiva. Pesquisa realizada com avós, tios e primos adotivos mostrou que a ocorrência de adoções na família ajuda a desmistificar os medos e os preconceitos, abrindo caminho para que outras adoções aconteçam (Dias \& Lima Neta, 2014).

Oliveira (2005) observou que o padrão de apego demonstrado na vida adulta é a evolução do modelo de apego que ficou internalizado e que foi vivenciado na infância. É o que se percebe na fala de Rute:

' $F$ ' me respeita e me ouve. Comigo, entre eu e ele não tem diferença de tratamento. Trato os meus dois irmãos da mesma forma. Hoje cada um vive sua vida sem problemas. As dificuldades, como eu já disse, foram na adaptação por causa da diferença de idade e por causa das atenções que foram voltadas pra ele. Mas depois a gente se acostuma. Ciúme é coisa de irmão mesmo, hoje que sou mãe já sei.

Um aspecto bem presente, especialmente nas falas de Raquel e de Moisés, foi o excesso de mimo e de superproteção, por parte de um dos pais para com seu filho adotivo. Para Rufo (2003), muitas vezes os pais ficam particularmente atentos aos filhos adotivos e próximos demais, para compensar não só "os traumas vividos pelo abandono", como a ausência dos laços de consanguinidade, o que favorece a rivalidade dos outros irmãos para com o (a) adotivo (a). No entanto, sabe-se que as frustrações são estruturantes para o desenvolvimento psíquico saudável e sua ausência acarreta prejuízos à criança, quer seja adotiva ou não. Otuka et al. (2012), por sua vez, pontuam que a superproteção pode ser uma forma compensatória de combater os preconceitos. Os autores postulam que assumir a diferença é uma forma de dignificar a singularidade.

\section{Considerações Finais}

Esta pesquisa teve como objetivo geral investigar as percepções e as experiências, na perspectiva de filhos biológicos, diante da chegada de um (a) irmão (ã) adotivo (a). No que se refere à reação diante da chegada do (a) 
irmão (ã) adotivo (a), a maioria dos entrevistados mostrou certa desorganização inicial, mas conseguiu manejar com sucesso a ambivalência de sentimentos nesse momento e nos subsequentes. Concordando com Rufo (2003) e Levinzon (2014), defendemos aqui a verbalização da origem da criança. Respostas claras e precisas permitirão ao filho adotivo sentir-se integrado à família e, aos biológicos, considerá-lo como verdadeiro irmão. Irmãos adotivos são diferentes de biológicos, pois as origens são diversificadas, mas os vínculos de apego independem dessa diferença.

As relações entre os irmãos em que a adoção foi precoce e o único caso em que o adotado era mais velho do que a participante também diferem. No primeiro caso, os irmãos crescem juntos e dividem experiências comuns por muito tempo. Já no caso da adoção tardia, as lembranças da vida pregressa estão vivas. A vida anterior, e quiçá a fratria anterior da criança recém-chegada não podem ser desconsideradas.

Os resultados evidenciaram que a chegada de um irmão adotivo na família pouco difere do que acontece com a chegada de irmãos consanguíneos. Observamos que, quando os participantes vivenciaram mais intensamente os preparativos para a chegada do irmão, a adaptação se processou de maneira mais fácil e despendeu menos tempo. Notamos também que a fratria existente assumiu papel essencial no acolhimento e na inserção da nova criança no sistema familiar.

Corroborando o que a literatura tem mostrado, a chegada do (a) irmão (ã) adotivo (a) mobilizou moções afetivas ambivalentes, mas, ao mesmo tempo, e na maioria dos depoimentos, sentimentos de colaboração. Por se tratar de entrevistas pontuais e não de acompanhamento psicológico ou pesquisa longitudinal, ficou difícil detectar se o fato de ser um irmão adotivo propiciou sentimentos diferentes dos vividos com a chegada dos irmãos consanguíneos. Há, portanto, necessidade de mais pesquisas que focalizem outras questões que atravessam o relacionamento entre irmãos. A título de sugestão, poderiam ser consideradas em futuras investigações: as percepções de cada membro da fratria; as concepções dos pais e da família extensa acerca do relacionamento entre os irmãos; a perspectiva da própria criança adotada; a questão da troca de lugares, especialmente nos casos de adoção de crianças mais velhas.

A convivência e a força do desejo dos pais de adotar tornaram-se elementos constitutivos fortes para a formação dos vínculos fraternos. Os pais precisam ajudar os irmãos a entender o comportamento do filho adotivo e propiciar que eles falem livremente sobre seu próprio medo de também ser abandonado ou de não satisfazê-los, bem como demonstrar respeito, imparcialidade e cuidado com cada um dos filhos (Brazelton \& Sparrow, 2007). Segundo esses autores, o filho biológico também pode ter medo de ser dado em adoção como uma forma de punição e, com isso, passar a ser uma criança extracomportada. Portanto, respeitar o ritmo dos envolvidos no grupo fraterno e permitir que o entrosamento entre eles ocorra com o tempo propiciado pelo convívio é mais adequado do que fazer imposições para que se deem bem.

Como observa Dolto (1998), todo filho, consanguíneo ou não, tem que ser adotado pelos pais e esse ato, ao mesmo tempo em que estabelece uma relação de igualdade, dando a cada um sentimento de pertencimento, é também ele que alimenta a fraternidade entre os irmãos.

\section{Referências}

Amaral, D. H., \& Dias, C. M. S. B. (2012). O subsistema fraterno na família recasada. Aletheia, 34, 123-137.

Braungart, J. M., Plomin, R., DeFries, C., \& Fulker, D. W. (1992). Genetic influence on Tester-Rated Infant Temperament as assessed by Bayley's Infant behavior record: nonadoptive and adoptive siblings and twins. Developmental Psychology, 28(1), 40-47.

Brazelton, B., \& Sparrow, J. (2007). Entendendo a rivalidade entre os irmãos (G. Klein, Trad.). Porto Alegre: Artmed.

Britto, N. (2002). Rivalidade fraterna: ódio e ciúme entre os irmãos. São Paulo: Ágora.

Carvalho, A. M. A., \& Bussab, V. S. R. (2013). Apego: o primeiro vínculo. In L. V. de C. Moreira (Orgs.), Psicologia, família e direito, interfaces e conexões (pp. 119-134). Curitiba: Juruá.

Crespo, R. M. (2013). Entre irmãos: um estudo sobre o cuidado criativo. Dissertação de Mestrado, Programa de Pós-graduação em Psicologia Clínica, Universidade Católica de Pernambuco.

Dellazana, L. L., \& Freitas, L. B. L. (2010). Um dia na vida de irmãos que cuidam de irmãos. Psicologia Teoria e Pesquisa, 26(4), 595-603.

Dias, C. M. S. B., \& Lima Neta, M. I, F. (2014). Adoção: percepções e vivências de avós, tios e primos adotivos. In C. Ladvocat \& S. Diuana (Orgs), Guia de adoção no jurídico, no social, no psicológico e na família (pp. 139-148). São Paulo: Roca.

Dolto, F. (1998). Destinos de crianças (E. Brandão, Trad.). São Paulo: Martins Fontes.

Eiguer, A. (2012). Filiação e adoção: reflexões cruzadas. In E. F. de Queiroz, \& M. C. Passos (Orgs), A clínica da 
adoção (pp. 141-156). Recife: Ed da UFPE.

Estatuto da Criança e do Adolescente (ECA). (1990). Presidência da República, Lei 8069 de 13/07/1990. Casa Civil, Brasília.

Freud, S. (1980). O mal-estar na civilização. In Edição Standard Brasileira das Obras Psicológicas Completas de Sigmund Freud (Vol. 21, pp. 81-171). Rio de Janeiro: Imago. (Originalmente publicado em 1929-1930).

Goldsmid, R., \& Féres-Carneiro, T. (2007). A função fraterna e as vicissitudes de ter e ser um irmão. Psicologia em Revista, 13(2), 293-308.

Goldsmid, R., \& Féres-Carneiro (2011). Relação fraterna: constituição do sujeito e formação do laço social. Psicologia USP, 22(4), 1-9.

Gomes, V. F., \& Bosa, C. (2004). Estresse e relações familiares na perspectiva de irmãos de indivíduos com Transtornos Globais do Desenvolvimento. Estudos de Psicologia, 9(3), 553-561.

James, S., Monn, A, Palinkas, L., \& Leslie, L. (2008). Maintaining sibling relationships for children in foster and adoptive placements. Children and Youth Services Review, 30, 90-106.

König, K. (1995). Irmãos e irmãs: um estudo em Psicologia Infantil (M. Motta, \& S. U. S. Aranha, Trad.). São Paulo: Antroposófica.

Lacan, J. (1977). La família. Buenos Aires: Homo Sapiens.

Levinzon, G. K. (2014). Parentalidade adotiva: os pais suficientemente bons. In C. Ladvocat \& S. Diuana (Orgs), Guia de adoção no jurídico, no social, no psicológico e na família (pp. 307-312). São Paulo: Roca.

Maldonado, M. T. (2006). Cá entre nós: na intimidade das famílias. São Paulo: Integrare Editora.

Meynckens-Fourez, M. (2000). A fratria, o ponto de vista eco-sistêmico. In E. Tilmans-Ostyn, \& M. MeynckensFourez (Orgs), Os recursos da fratria (pp. 19-53, C. A. Molina-Loza \& A. M. Prates, Trad.). Belo Horizonte: Artesã.

Minayo, M. C. (2004). O desafio do conhecimento: pesquisa qualitativa em saúde ( $8^{\mathrm{a}} \mathrm{ed}$.). Rio de Janeiro: HUCITEC.
Nunes, C. C., \& Aiello, A. L. R. (2007). Interação entre irmãos: deficiência mental, idade e apoio social da família. Psicologia Reflexão e Crítica, 19, 395-406.

Oliveira, A. L. de (2005). Irmãos, meio irmãos e co-irmãos: a dinâmica das relações fraternas no recasamento. Tese de Doutorado, Programa de Pós-graduação em Psicologia Clínica, Pontifícia Universidade Católica de São Paulo.

Otuka, L. K., Scorsolini-Comin, F., \& Santos, M. A. (2012). Adoção suficientemente boa: experiência de um casal com filhos biológicos. Psicologia Teoria e Pesquisa, 28(1), 55-59.

Paulo, B. (2006). Novas configurações familiares e seus vínculos sócio-afetivos. Dissertação de Mestrado, Programa de pós-graduação em Psicologia, Pontifícia Universidade Católica do Rio de Janeiro.

Pereira, C. R. R., \& Arpini, D. M. (2012). Os irmãos nas novas configurações familiares. Psicologia Argumento, 30(69), 275-285.

Pereira, C., \& Piccinini, C. (2007). O impacto da gestação do segundo filho na dinâmica familiar. Estudos de Psicologia, 24(3), 385-395.

Perez, A. (2002). O filho primogênito: suas características e seus relacionamentos no contexto familiar. In A. Wagner (Org.), Família em cena: tramas, dramas $e$ transformações (pp. 113-131). Petrópolis,RJ: Vozes.

Pichon-Rivière, E. (2000). Teoria do vínculo (6a. ed., E. T. Zamikhouwsky, Trad.). São Paulo: Martins Fontes.

Raspantini, R., \& Escrivão, M.V. (2003). Dos laços de sangue aos laços de ternura: o processo de construção da parentalidade nos pais adotivos. Psic, 4(1), 14-21.

Rufo, M. (2003). Irmãos: como entender essa relação (P. Abreu, Trad.). Rio de Janeiro: Nova Fronteira.

Schettini Filho, L. (1999). Adoção: origem, segredo e revelação. Recife: Bagaço.

Souza, M. P. G., Franco, A. L. S., \& Carvalho, A. M. A. (2009). Crianças que cuidam de irmãos com necessidades especiais. Psicologia Teoria e Pesquisa, 25(1), 45-54.

Silveira, L. (2002). O relacionamento fraterno e suas características ao longo do ciclo vital da família. In A. Wagner (Org.), Família em cena: tramas, dramas 
e transformações (pp. 93 -112). Petrópolis,RJ: Vozes.

\section{Endereço para correspondência:}

Cristina Dias

Endereço: Rua Conselheiro Portela, no 130 A, apto. 201, Graças. Recife/PE, CEP: 52020-212.

E-mail: cristina.msbd@gmail.com

Endereço para correspondência:

Edilene Queiroz

Endereço: Rua Conselheiro Portela, no 130 A, apto. 201, Graças. Recife/PE, CEP: 52020-212.

E-mail: edilenefreiredequeiroz@gmail.com 